\title{
Corrigendum: Peptide-MHC potency governs dynamic interactions between T cells and dendritic cells in lymph nodes
}

Dimitris Skokos, Guy Shakhar, Rajat Varma, Janelle C Waite, Thomas O Cameron, Randall L Lindquist, Tanja Schwickert, Michel C Nussenzweig \& Michael L Dustin

Nat. Immunol. 8, 835-844 (2007); published online 15 July 2007; corrected after print 19 October 2007

In the version of this article initially published, the legends for Figures 1 and 5 are incorrect. The correct phrasing should be, for Figure 1a, “... injection of $\alpha$-DEC-MCC, $\alpha$-DEC-APL constructs, $\alpha$-DEC-ovalbumin ( $\alpha$-DEC-OVA), $\alpha$-DEC-205 plus isotype-MCC ( $\alpha$-DEC + iso-MCC) or for Figure 5, “...mice were injected with $\alpha$-DEC-APL constructs and then, $5 \mathrm{~h}$ later, with Fluo-4 AM- and CMRA-colabeled AND T cells" on line 2, and "Frequency of AND T cells with 'sustained' Ca2 ${ }^{+}$increase in mice treated..." on line 3. The errors have been corrected in the HTML and PDF versions of the article.

\section{Corrigendum: Regulation of naive T cell function by the NF-kB pathway}

\author{
Naozumi Ishimaru, Hidehiro Kishimoto, Yoshio Hayashi \& Jonathan Sprent \\ Nat. Immunol. 7, 763-772 (2006); published online 28 May 2006; corrected after print 19 October 2007
}

In the version of this article initially published, the sentence on page 763, column 2, line 12 is incorrect. The correct sentence should end “...and these mice show increased susceptibility to typhlocolitis and infection with Leishmania major but are resistant to experimental autoimmune encephalomyelitis and asthma ${ }^{14-17}$." The error has been corrected in the PDF version of the article.

\section{Corrigendum: Ligand-induced conformational changes allosterically activate Toll-like receptor 9}

Eicke Latz, Anjali Verma, Alberto Visintin, Mei Gong, Cherilyn M Sirois, Dionne C G Klein, Brian G Monks, C James McKnight,

Marc S Lamphier, W Paul Duprex, Terje Espevik \& Douglas T Golenbock

Nat. Immunol. 8, 772-779 (2007); published online 17 June 2007; corrected after print 19 October 2007

In the version of this article initially published, the distance values reported in Tables 1 and 2 are incorrect. The correct values are provided in the revised tables. Accordingly, line 6 on p 774 should read " 7.3 nm"; line 11 on p 774 should read "a $12 \%$ decrease"; line 12 on p 777 should read "7.0 nm"; and lines 17-20 on p 777 should read "We calculated the C-terminal intermolecular distance in the endosome to be less 5.4 nm. Given the fact that the donor and acceptor fluorophores are buried inside the fluorescent proteins, their minimal distance is approximately 5.0 nm. Thus, these measurements indicate that the TLR9 TIR domains were brought in close proximity after the binding of CpG DNA ligand to the TLR9 ectodomains (Table 2)." The error has been corrected in the HTML and PDF versions of the article.

\section{Corrigendum: The clonal selection theory: 50 years since the revolution}

Philip D Hodgkin, William R Heath \& Alan G Baxter

Nat. Immunol. 8, 1019-1026 (2007); corrected after print 19 October 2007

In the version of this article initially published, the corresponding author information is incorrect. The correct e-mail addresses should be as follows: Alan.Baxter@jcu.edu.au and hodgkin@wehi.edu.au. The error has been corrected in the HTML and PDF versions of the article. 